\title{
IAC-04-Q.P.05
}

\section{WATER ON MARS: \\ EVIDENCE FROM MER MISSION RESULTS}

\author{
Geoffrey A. Landis \\ NASA John Glenn Research Center \\ 21000 Brookpark Road, \\ Cleveland $\mathrm{OH} 44135$ USA \\ 216-433-2238 \\ fax: $216-433-6106$ \\ and
}

The Athena Science Team

NASA Jet Propulsion Laboratory

Pasadena, CA 91101

\begin{abstract}
The Mars Exploration Rover (MER) mission landed two rovers on Mars, equipped with a highly-capable suite of science instruments. The Spirit rover landed on the inside Gusev Crater on January 5, 2004, and the Opportunity rover three weeks later on Meridiani Planum. This paper summarizes some of the findings from the MER rovers related to the NASA science strategy of investigating past and present water on Mars.
\end{abstract}

\section{INTRODUCTION}

\subsection{Overview}

The Mars Exploration Rover (MER) mission launched two highly capable science rovers to Mars in 2003 [1,2]. This paper reviews some of the findings from the MER mission related to the NASA science strategy of investigating past and present water on Mars. Details of the scientific results of the MER mission can be found in numerous reports on the mission [3-12].

\subsection{The Mars Science Strategy}

Observations of Mars from orbit show signs of geological alteration by large amounts of liquid water, although there are no significant bodies of liquid water today existing on the surface [13]. Landing sites for the MER mission were selected using the
NASA Mars science strategy, which can be summarized by the motto "follow the water." The Mars exploration strategy proposes that the environment, climate and history of the Martian surface can be unraveled by a campaign to understand the past and present role of water. Implementation of this science strategy has included visible light and laser altimetry investigations of Mars from the Mars Global Surveyor (MGS) spacecraft, mapping the global distribution of water ice by measuring hydrogen using epithermal neutron detection from the Mars-2001 Odyssey spacecraft, and measuring the mineralogy of Mars, including hydrated minerals and other aqueous alteration products, using the TES and THEMIS infrared instruments on both the MGS and Odyssey spacecraft. 


\subsection{The MER mission}

The MER mission continues this study of water on Mars by investigating water-related features on the Martian surface, using a suite of chemical, physical, and mineralogy measurement instruments [2].

The site selected for the landing of the first rover, Spirit, was a location near the center of Gusev Crater [14], a 150-km diameter crater with a depth of about $1.6 \mathrm{~km}$. The Gusev crater site was chosen from orbital images as being the possible site of a former Martian lake, with an inflow channel, Ma'adim Vallis, and signs of an outflow spillway visible from Mars orbit (Figure 1 and 2).

The landing site chosen for Opportunity, the second rover, was Meridiani Planum [14]. This site was selected because thermal emission spectroscopy of the landing location from orbit indicated the spectral signature of hematite. On Earth, hematite is a mineral that forms primarily either in aqueous environments, or as a result aqueous alteration. While the Martian environment may support mechanisms for formation of hematite that are different from the mechanisms of hematite formation seen on Earth, the presence of hematite is of great scientific interest, and was also seen as a possible indication of past water.



Figure 1: Gusev crater viewed from orbit, shows signs of past water activity.

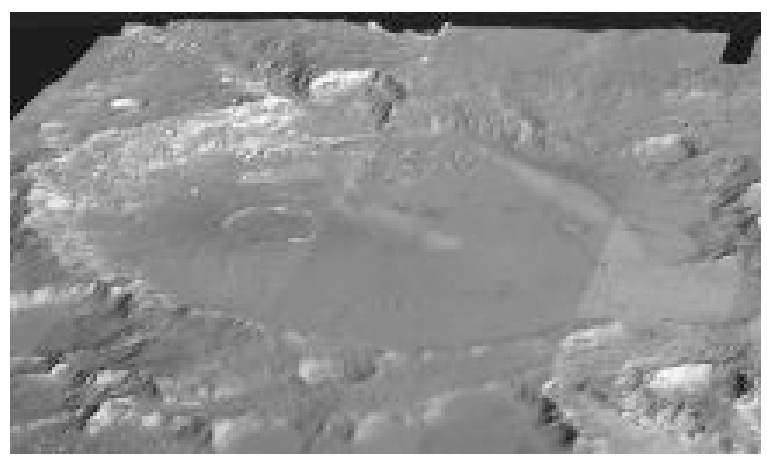

Figure 2: Gusev crater shown in a computergenerated perspective view.

Spirit landed successfully on the plains inside Gusev Crater on January 5, 2004. Opportunity bounced down three weeks later on Meridiani Planum, making a "hole-in-one" landing inside a small crater nicknamed by the science team "Eagle Crater."

After Spirit and Opportunity drove off their airbag landing platforms onto the surface, each rover successfully accomplished their 90-sol (92 Earth-day) primary missions of exploration. As of this writing, both rovers are continuing to function, operating to date for nearly three times their primary mission lifetime.

The operation of the two rovers on Mars has generated exceptional public interest. Over the first months after landing, the MER web site received over ten billion hits. This is an order of magnitude more than the total number of hits recorded by any government agency (including NASA) in all of the previous year.

\section{LIQUID WATER}

\subsection{Water Evidence from Opportunity:}

\section{Sulfate Mineralogy}

The layered outcrop rocks seen at the Opportunity landing site showed numerous signs of past water on Mars. The "Eagle Crater" landing site proved to be a fortuitous location, in that the crater impact evacuated through the surface, and removed the regolith to expose and section the outcrop of rock beneath (figure 3 ). 


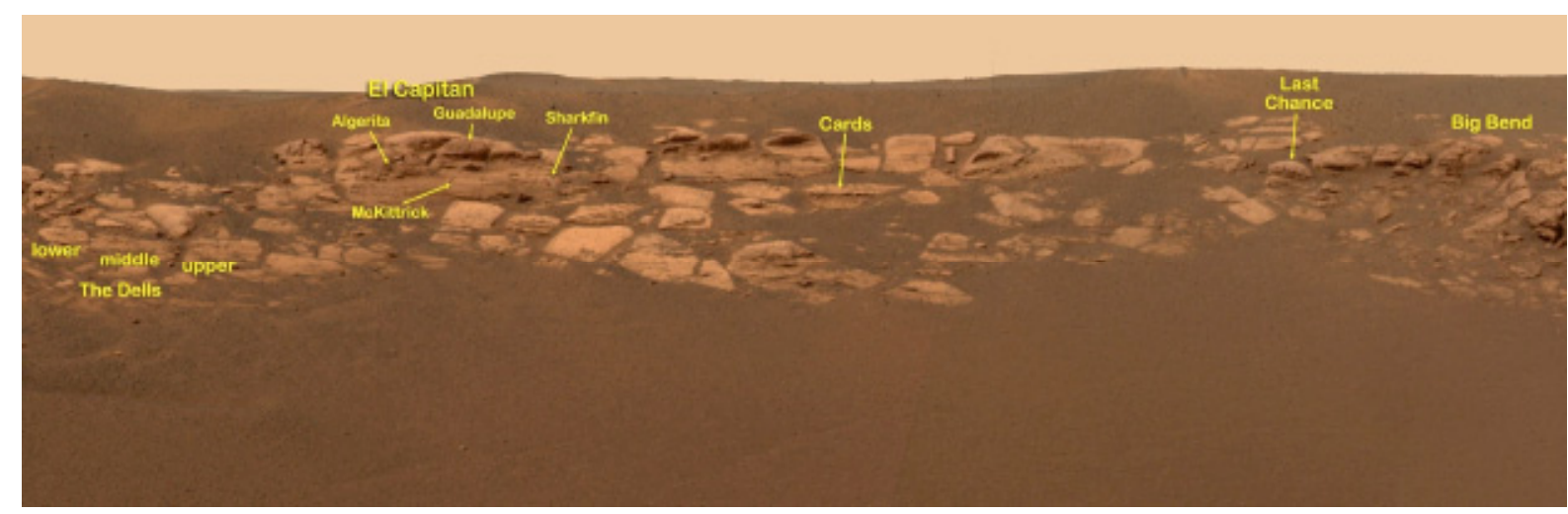

Figure 3: Layered rocks of the Eagle crater outcrop, as imaged by pancam on the Opportunity Rover, showing the names and location of rocks discussed. Image credit: NASA/JPL/Cornell.

The rock of the Eagle crater outcrop are layered, apparent sedimentary in origin. Specific signs of an origin or alteration period involving liquid water include: sulfate evaporite mineralogy (jarosite), hematite concretions, vugs, cross-bedding, and fracture filling. A review of the evidence for an aqueous origin for the rocks seen in the outcrop at Eagle crater is found in reference [3].

This paper reviews some of the main results; more detailed discussion of the science findings from Meridiani are found in references [3-11].

\subsection{Mineralogy at the Meridiani Site}

The alpha particle X-ray spectrometer (APXS) instrument on Opportunity detected abundant sulfur in the outcrop [6,7]. Figure 4 shows an example APXS spectrum, comparing the rock "McKittrick" to a nearby patch of basaltic soil ("Tarmac"). The rock shows higher concentrations of sulfur and bromine

The thermal IR signature, measured by the miniature thermal emission spectrometer ("miniTES") instrument [8], fits well to a signature of minerals containing a composition of $20-40 \%$ calcium or magnesium sulfate. These sulfate salts show indications of being evaporites, an indicator that the site was once soaked with water.

Figure 5 summarizes the relative abundances of sulfate (assumed to be $\mathrm{SO}_{3}$ ) and chloride in three Meridiani Planum targets: soil; the rock "McKittrick," and the rock "Guadalupe" in the outcrop. The data from the two rocks is shown both before and after the rover used the rock abrasion tool to expose fresh rock underneath. Note that the sulfur composition increases when the outer layer of rock is removed, showing that the sulfate is in the rock, and is not an external dust coating or rind. After grinding, the sulfur abundance for both rocks rose to high levels, nearly five times higher than that of the soil. This very high sulfur concentration reflects a heavy presence of sulfate salts (approximately 30 percent by weight) in the rocks.

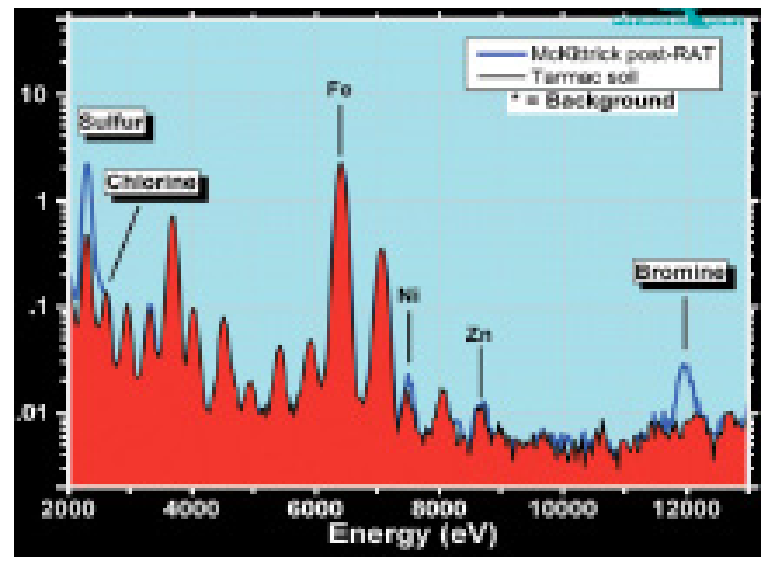

Figure 4: APXS data from the rock "McKittrick" at Meridiani Planum compared to soil, plotting counts per second (logarithmic scale) versus energy. Image credit: NASA/JPL/Cornell/Max Planck Institute 


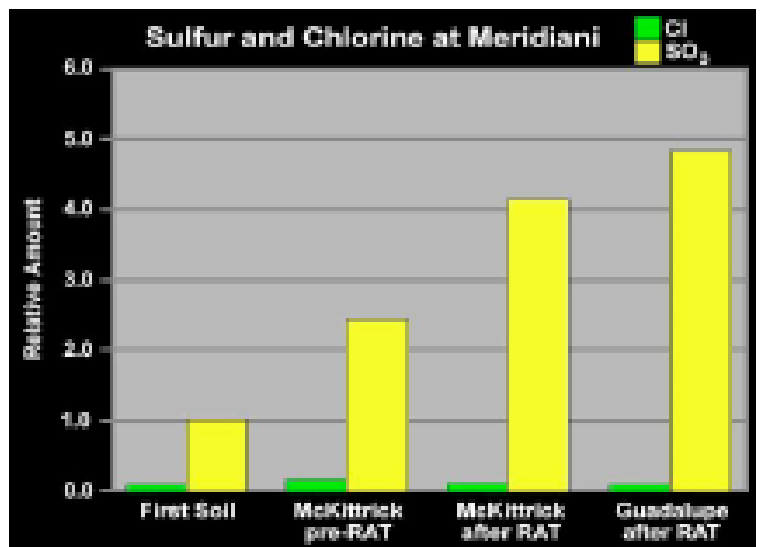

Figure 5: Relative abundances of sulfate (assumed to be $\mathrm{SO}_{3}$ ) and chloride in three Meridiani Planum targets: soil, the rock "McKittrick," and the rock "Guadalupe" in the outcrop. Composition from McKittrick is shown both before and after abrasion to expose fresh rock surface. Image credit: NASA/JPL/Cornell/Max Planck Institute

Figure 6 shows iron mineralogy measured by the Mössbauer spectrometer [9-11] on a typical outcrop rock. The best fit to this spectrum indicates a composition containing the mineral jarosite (nominal composition $\left.(\mathrm{K}, \mathrm{Na}) \mathrm{Fe}_{3}\left(\mathrm{SO}_{4}\right)_{2}(\mathrm{OH})_{6}\right)$, an iron sulfate mineral which contains water in the form of hydroxyl as a part of its structure.

Jarosite in the outcrop accounts for $\sim 28 \%$ of total the total iron. This is direct mineralogical evidence for oxidative aqueous alteration of basaltic precursors, which could result from rock deposition or alteration from an acidic lake or acidic hot springs environment.

Reference [3] discusses the suggested origin and mineralogy of the jarosite outcrops in more detail.

Three other iron phases are also identified in the Mössbauer spectrum: a magnetic phase, attributed to an iron-oxide mineral; a silicate phase, indicative of minerals containing double-ionized iron ( $\mathrm{Fe} 2+$ ); and a third phase of minerals with triple-ionized iron ( $\mathrm{Fe} \mathrm{3+}$ ).

Related compositional evidence of water is the findings of chlorine and bromine in the rocks (figure 5). Such high levels of salts strongly suggest the rocks contain evaporite deposits, which form when water evaporates or ice sublimes into the atmosphere. Bromine findings are significant evidence of rocks forming from precipitation of surface water as salt concentrations climbed past saturation while water was evaporating. A notable measurement is the fact that the bromine to chlorine ratio varies with rocks measured at different elevations, with the highest rocks measuring the highest bromine concentrations. This is consistent with the hypothesis of rocks formed by precipitation from solution, since the differential solubility of bromide compared to chloride means that chloride will deposit more readily than bromide, resulting in an enhancement of bromine in the latest deposition.

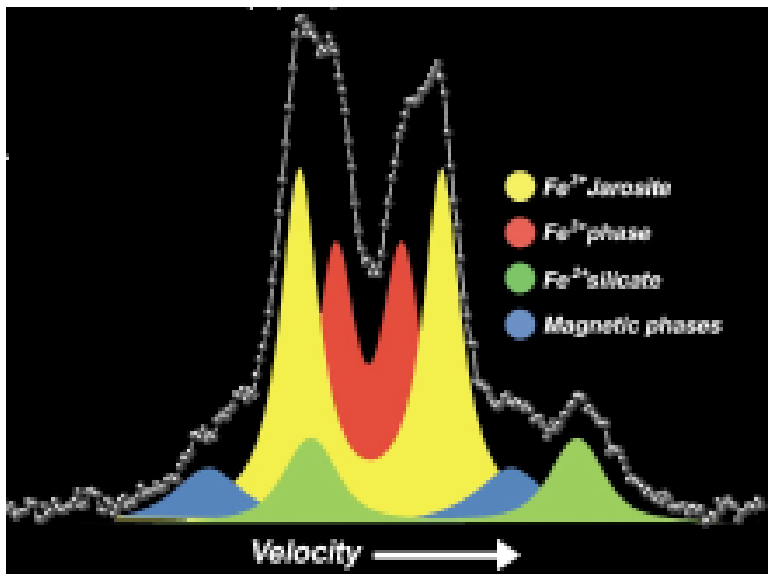

Figure 6: Mössbauer spectrum [9] from Opportunity of the outcrop "El Capitan" in Eagle crater, along with the best fit to the composition of iron-bearing minerals. The highest peaks indicate iron contained in a jarosite phase. Image credit: NASA/JPL/ University of Mainz.

\subsection{Rocks at the Meridiani Site}

Pancam and Microscopic Imager (MI) views of an outcrop rock selected for close-up examination show numerous vugs, small randomly-oriented holes of an elongated prismatic shape. These vugs match the distinctive appearance of terrestrial rock vugs formed where crystals of salt minerals grow 
inside rocks that in high-salt water, then disappear by eroding or dissolving.

A characteristic feature of the Meridiani site, both inside the crater and on the plains outside, is numerous 4-6 $\mathrm{mm}$ grey spheres (nicknamed "blueberries), which are found both in the soil (figure 8), and also embedded in outcrop rocks (figure 9). Figure 8 shows a location where three spherules have grown together, indicating that the spherical shape is the as-grown shape, not a shape caused by erosion. The composition of these spherules, as indicated by APXS and miniTES measurements [3], is primarily grey hematite, $\mathrm{Fe}_{2} \mathrm{O}_{3}$. They are believed to be concretions that formed from accumulation of minerals precipitating out of solution inside a porous, water-soaked rock. Hematite is pervasive and is found both in the outcrop matrix (where it accounts for about $35 \%$ of total $\mathrm{Fe}$ ) and in the spherules.

Bedding patterns in the rocks indicates deposition by water. Figure 7 shows one rock from the Eagle crater outcrop, where fine, parallel laminations can be seen through the rock (particularly visible in the upper area). Also visible are scattered vugs, or small surface cavities, about 1 centimeter long.

Some finely layered rocks indicate the sand-sized grains of sediment that eventually bonded together were shaped into ripples by water at least five centimeters deep, possibly much deeper, and flowing at a speed of 10 to 50 centimeters per second. Figure 9 shows a Microscopic-imager mosaic of a portion of the rock outcrop, showing fine laminae that are truncated, discordant and at angles to each other. The direction of the ancient flow would have been toward or away from the viewer. Figure 10 shows a view of a layered outcrop rock, with the bedding planes marked. This evidence for trough crosslamination, likely produced when flowing water shaped sinuous ripples in underwater sediment and pushed the ripples to migrate in one direction.

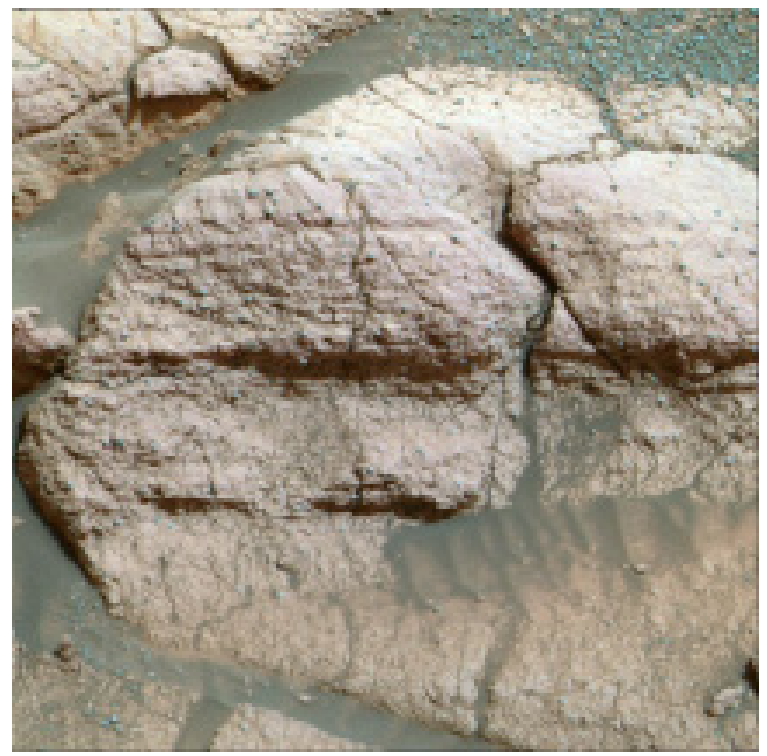

Figure 7: The rock outcrop "El Capitan," in Meridiani Planum, viewed by the pancam on Opportunity. Fine laminations can be seen in the rock, which also contains scattered sphere-shaped hematite concretions ("blueberries") a few millimeters in size. Also visible are scattered vugs, or small surface cavities. (Colors in this image have been enhanced.) Image credit: NASA/JPL.

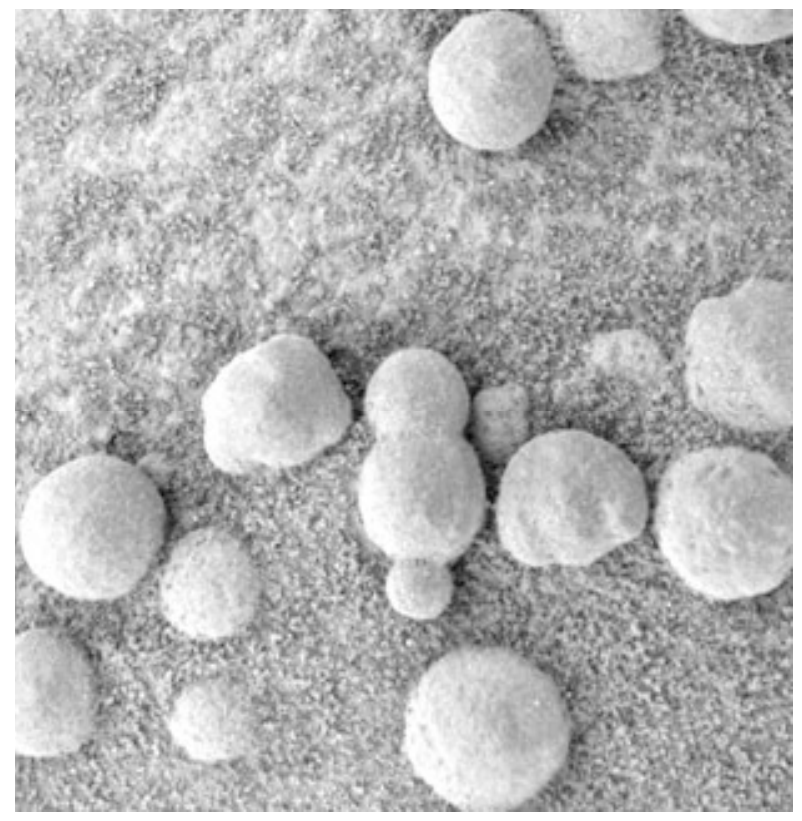

Figure 8. Hematite concretions in the soil, seen by the microscopic imager on the Opportunity rover. Near the center three spherules are partially grown together. Image credit: NASA/JPL/US Geological Survey. 




Figure 9. MI mosaic [12] of the rock "Upper Dells," showing hematite spherules embedded in the rock and details of layering. Image credit: NASA/JPL/Cornell/USGS

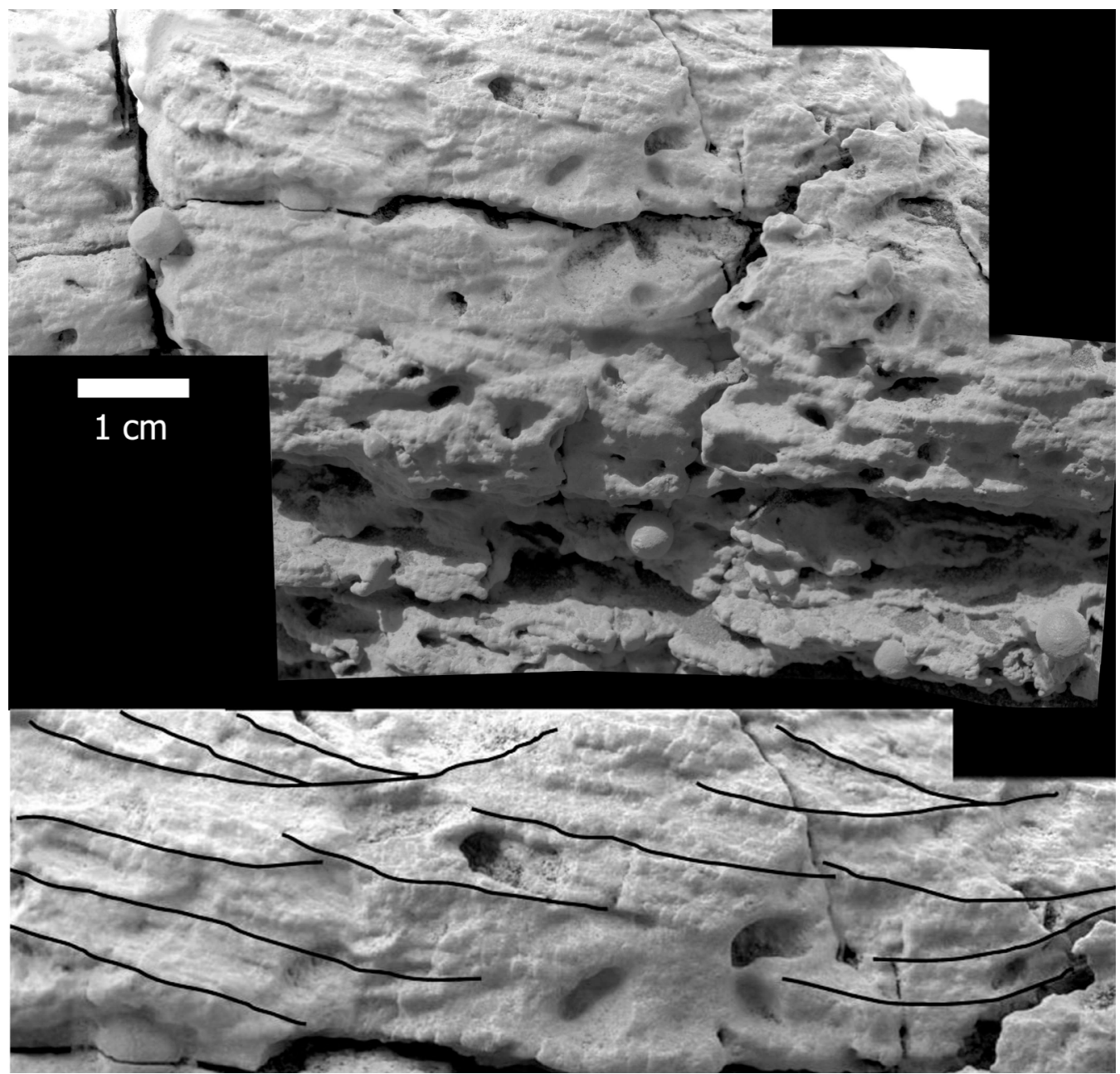

Figure 10: Cross-bedding in the rock "Last Chance," shown from the Microscopic Imager [12] on Opportunity. Top: Microscopic-imager mosaic. Bottom: detail of upper portion of image, with bedding planes traced out. Image credit: NASA/JPL/Cornell 
The conclusion of the investigation of the Eagle crater site indicate that the bedrock at the site was most likely formed during the evaporation of a low-pH body of water containing a high concentration of sulfidecontaining salts.

\subsection{Water Evidence from Spirit}

The Gusev landing site of the Spirit rover showed less obvious signs of water. However, even at the Gusev site, the basaltic rocks show several lines of evidence of modification by water [15]. These signs included the soil crusts and rock coatings on the plains inside the crater, and the presence of layered rock and possible evaporitic material at the "Columbia Hills" sites being explored during the extended missions. This could be from water in the atmosphere, interactions by ground water, or surface water.

A significant finding is the presence of a sulfate-salt coating on some of the rocks at the site. This coating seems to be closely associated with rocks that have been buried and recently exhumed, and may be a sign of salt coating due to a liquid phase of groundwater. Evidence that this coating is emplaced by liquid water comes from examination by the microscopic imager of a narrow fracture line in a light-colored rock. The fracture is filled by a lighter-colored material. This fill is evidently a sulfate, transported into the fracture as a solution, which then precipitated in the crevice to form the light-colored vein.

At both Meridiani Planum and Gusev Crater, basaltic surface soils show significant concentrations of nanophase ferric oxide. This suggests that Martian dust is basaltic in bulk composition and may be a product of oxidative, possibly aqueous alteration.

\subsection{Evidence of Recent Water}

The Viking and the Mars Exploration Rover missions observed that the surface of Mars is encrusted by a thinly cemented layer tagged as "duricrust". Figure 11 shows a paper IAC-04-Q.P.05, International Astronautical Federati trench in the soil [16] cut by the Spirit rover's wheel, with the crusty top layer quite visible. A hypothesis to explain the mechanisms by which these surface materials become cemented is that the soil is cemented by salts [17].

Elemental analyzes at five sites on Mars show that these soils have high sulfur and chlorine content $[18,19]$. At the MER-A site in Gusev crater, APXS measurement shows the soil to contain from 0.45 to $0.61 \%$ chloride and $4-6.2 \%$ sulfate by weight. For comparison, rocks at the same site (after the dusty exterior layer was removed) showed $0.15-0.23 \%$ chloride and $1-1.1 \%$ sulfate $[7$, 20]. The soil is highly enriched in the saltforming elements compared with rock. These findings are consistent with the presence of sulfates and halides as mineral cements. The soil is highly enriched in the salt-forming elements compared with rock. Analysis of the soil cementation indicates some features which may be evidence of liquid water.

Figure 12 shows a microscopic-imager view [21] of cemented soil from the Gusev site. Duricrust textures $[16,21]$ revealed by the Microscopic imager show features including the presence of fine sand-sized grains, some of which may be aggregates of fine silt and clay, surrounded by a pervasive light colored material that is associated with microtubular structures and networks of microfractures. Stereo views of undisturbed duricrust surfaces reveal rugged microrelief between 2-3 $\mathrm{mm}$ and minimal loose material. Comparisons of microscopic images of duricrust soils obtain before and after placement of the Mössbauer spectrometer indicate differing degrees of compaction and cementation.

Two models of a transient water hypothesis are possible [17], a "top down" hypothesis that emphasizes the surface deposition of frost, melting and downward migration of liquid water and a "bottom up" alternative that proposes the presence of interstitial ice/brine, with the upward capillary 
migration of liquid water. The viability of both of these models ultimately hinges on the availability of transient liquid water for brief periods [22], either on a seasonal basis, or else during a climate epoch in which the conditions are favorable for liquid formation.

At the elevation of the landing sites of all Mars missions to date, including the Mars Exploration Rovers, the atmospheric pressure lies above the triple point pressure of liquid water. At night, soil and rock temperatures are cold enough (e.g., about $-100 \mathrm{C}$ at the Gusev site) to allow a small amount of water to condense on or between the grains. Measurements of the surface temperature by the miniTES instrument indicate that the daytime temperature rises well above $273 \mathrm{~K}$, high enough for the deposited ice to melt into a liquid phase.

In the "top down" model, this deposited frost is warmed by the daytime temperature rise to form a transient liquid phase, which migrates downward (assisted by capillary action), in the process dissolving any salt present. Surface tension in the liquid pulls the

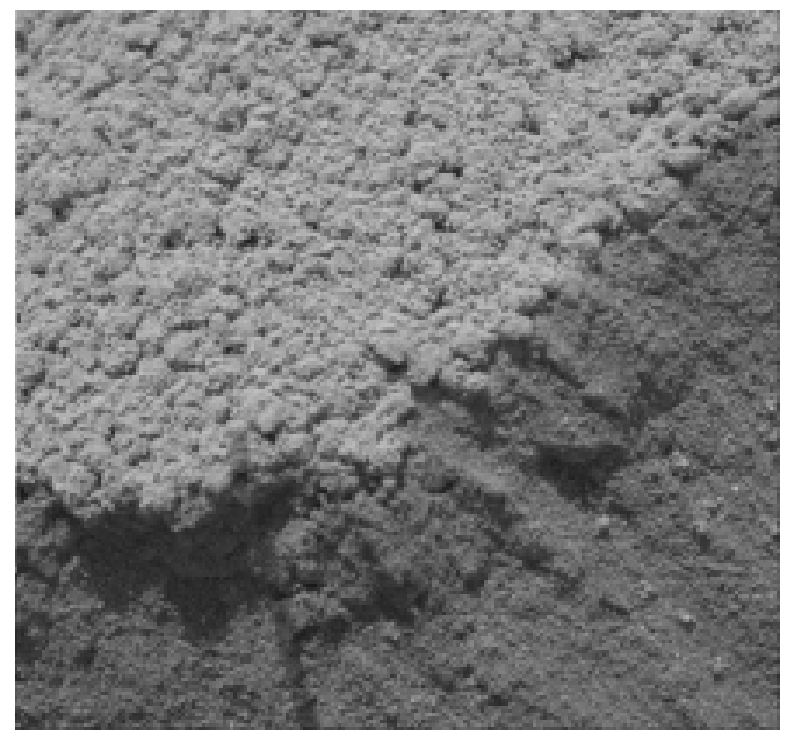

Figure 11: Duricrust viewed from the Microscopic imager [21] at the edge of a trench cut by the Spirit rover wheel [16]. (frame is approximately $3 \mathrm{~cm}$ across). Image credit: NASA/JPL/Cornell. gains together. As the soil heats further, the water evaporates, and the remaining salts cement the grains to form the duricrust. New aeolian dust and sand brings further material to the site, allowing the surface crust layer to thicken. The condensation can be in the form of a surface ice layer condensing directly on the rocks ("frost"), as ice accreting on dust grains in the atmosphere, causing them to precipitate onto the soil ("snow"), or in the form of condensation of liquid droplets of water in the atmosphere ("fog"). Each of these condensation mechanisms operates under different atmospheric and surface temperature conditions.

In the alternative "bottom up" hypothesis, liquid from a subsoil brine or ice reservoir is drawn upward by capillary forces toward the surface, where it evaporates, depositing any dissolved salts present.

In both cases, dissolved salts and capillary-pore effects in the soil [22] will tend to extend the liquid range of the water, allowing the process to operate over a wider range of temperatures.



Figure 12: Soil of "Laguna Hollow" viewed from Spirit Rover Microscopic Imager [21], showing cementing of grains by a lightcolored soil component. (Image is about $1 \mathrm{~cm}$ across). Image credit: $N A S A / J P L /$ Cornell. 
The melting-point depression will depend on the salt composition and on the $\mathrm{pH}$. Assuming the dominant salt is sulfate, for example, the eutectic salt $\left(0.13 \mathrm{Na}_{2} \mathrm{SO}_{4}+0.87\right.$ $\mathrm{MgSO}_{4}$ ) has a freezing point of $266 \mathrm{~K}$. Chloride addition will depress the melting point further, extending the liquidus range.

Repetition of this process over long time spans could produce a coherent zone of cementation. These models, which emphasize interactions between the atmosphere and soils, appear to be quite plausible under present Martian climatic/atmospheric conditions and could explain the apparently widespread distribution of cemented soils on Mars, over a broad range of elevations latitudes.

This transient-water model offers an explanation for the process of cementation, its widespread distribution and compositional and textural features of crusts. The presence of sulfates and chlorides, both common evaporite minerals may be compared with potentially analogous settings on Earth, such as cemented playa surfaces and duricrusts of terrestrial deserts.

The model additionally explains the presence of salt-cemented surface coatings on rocks, as the transient water leeches salts out of air-fall dust deposits, and cements these into a surface rind. Such salt-rich rinds are seen on rocks at the Gusev site.

\section{CONCLUSIONS}

From the MER mission, a picture of Mars is emerging as a planet with a past history that has included shallow seas of sulfur-rich, low$\mathrm{pH}$ water that has evaporated away to leave traces in the form of sulfate and halide salts in the soil and in the form of sulfate-rich evaporate beds.

\section{ACKNOWLEDGEMENTS}

This work was supported by the NASA Office of Space Science. The science results of the MER mission have been a team effort. The authors would like to thank each of the
Athena Science Team members, the MER mission operations team, and the tireless support staff at JPL, Cornell, and elsewhere, who worked innumerable $24-2 / 3$ hour days to ensure that the mission would be the success that it has been.

\section{NOTE ON FEATURE NAMES}

The informal names used here for geographic features and rock targets have been assigned by the science team for planning and operations purposes, and are not formally recognized by the International Astronomical Union.

\section{REFERENCES}

[1.] J. Erickson, M. Adler, J. Crisp, A. Mishkin, and R. Welch, "Mars Exploration Rover Surface Operations," paper IAC-02Q.3.103, 53rd International Astronautical Congress, October 10-19, 2002, Houston, TX.

[2.] S. W. Squyres et al., "Athena Mars Rover Science Investigation," J. Geophysical Res., Vol. 108, No. E12, 8062 (2003).

[3.] S. W. Squyres, et al., "The Spirit Rover's Athena Science Investigation at Gusev Crater, Mars," Science, Vol. 305, No. 5685, 794-799, 6 August 2004.

[4.] S. Squyres, et al., "In-Situ Evidence for an Ancient Aqueous Environment on Mars," Science, Vol. 305 (in press), 2004.

[5.] R.E. Arvidson, et al., "Geology of Meridiani Planum as Inferred from Mars Exploration Rover Observations," in Lunar \& Planetary Science $X X X V$ (LPI Publication 1197, 2004). Presented at the 35th Lunar and Planetary Science Conference, League City TX, Mar 15-19 2004.

[6.] R. Rieder, et al., "Chemical Composition of Martian Rocks and Soils at Meridiani Planum from the Alpha Particle Xray Spectrometer," Science, Vol. 305 (in press), 2004.

[7.] R. Rieder, et al., "APXS on Mars: Analyses of Soils and Rocks at Gusev Crater and Meridiani Planum," in Lunar \& Planetary 
Science XXXV (LPI Publication 1197, 2004). Presented at the 35th Lunar and Planetary Science Conference, League City TX, Mar 15-192004.

[8.] P. R. Christensen, et al., "Mineral compositions and abundances at the Meridiani Planum Site from the Mini-TES Experiment on the Opportunity Rover," Science, Vol. 305 (in press), 2004.

[9.] G. Klingelhöfer, et al., "Jarosite and Hematite at Meridiani Planum from the Mössbauer Spectrometer on the Opportunity Rover," Science, Vol. 305 (in press), 2004.

[10.] G. Klingelhöfer, et al., "Meridiani Planum: Geochemistry and Mineralogy," European Geophysical Union meeting, Nice, France (April 25-30, 2004).

[11.] R. V. Morris, G. Klingelhöfer, and the Athena Science Team, "Mössbauer Mineralogical Evidence for Aqueous Processes at Gusev Crater and Meridiani Planum," CGU, AGU, SEG and EEGS 2004 Joint Assembly, Montreal, Canada, 1721 May 2004.

[12.] K. E. Herkenhoff, et al., "First Results of the Opportunity Microscopic Imager Investigation," Science, Vol. 305 (in press), 2004.

[13.] M. Carr, Water on Mars, Oxford University Press, 1995.

[14.] M. P. Golumbek et al., "Selection of the Mars Exploration Rover Landing Sites," $J$.
Geophysical Res., Vol. 108, No. E12, 8072 (2003).

[15.] L. A. Haskin, et al., "Water Alteration of Rocks and Soils from the Spirit Rover Site, Gusev Crater, Mars," (in preparation to be submitted to Nature (2003)).

[16.] R. Arvidson, et al., "Localization and Physical Properties Experiments Conducted by Spirit at Gusev Crater," Science, Vol. 305, No. 5685, 821-824, 6 August 2004.

[17.] G. A. Landis, et al., "Transient Liquid Water as a Mechanism for Induration of Soil Crusts on Mars," in Lunar \& Planetary Science XXXV (LPI Publication 1197, 2004). Presented at the 35th Lunar and Planetary Science Conference, League City TX, Mar 15-19 2004.

[18.] B. C. Clark, et al., J. Geophysical Res., Vol. 87, 10059 (1982).

[19.] R. Rieder, et al., Science, Vol. 278, 1771 (1997).

[20.] R. Gellert, et al., "Chemistry of rocks and soils in Gusev crater from the Alpha Particle X-Ray spectrometer," Science, Vol. 305, No. 5685, 829-832, 6 August 2004.

[21.] K. E. Herkenhoff, et al., "Texture of the soils and rocks at Gusev crater from Spirit's Microscopic Image," Science, Vol. 305, No. 5685, 824-826, 6 August 2004. (2004).

[22.] G. A. Landis, "Martian Water: Are there Extant Halobacteria on Mars?" Astrobiology, Vol. 1, No. 2, 161-164 (2001). 